\title{
Human Adipose Stem Cells Exposed to Gamma Radiation and Inactivity (Stasis) Show Increased Cancer Markers and DNA Damage. A Preliminary Assessment of a Pharmaceutical Formulation to Reverse These Effects and Its Applications for Medical Radiotherapy and the Space Industry
}

\author{
E. Russell Vickers \\ Clinical Stem Cells PL, Sydney, Australia \\ Email: manager@clinicalstemcells.com
}

How to cite this paper: Vickers, E.R. (2022) Human Adipose Stem Cells Exposed to Gamma Radiation and Inactivity (Stasis) Show Increased Cancer Markers and DNA Damage. A Preliminary Assessment of a Pharmaceutical Formulation to Reverse These Effects and Its Applications for Medical Radiotherapy and the Space Industry. Journal of Cancer Therapy, 13, 7-19. https://doi.org/10.4236/jct.2022.131002

Received: December 6, 2021 Accepted: January 9, 2022

Published: January 12, 2022

Copyright $\odot 2022$ by author(s) and Scientific Research Publishing Inc. This work is licensed under the Creative Commons Attribution International License (CC BY 4.0).

http://creativecommons.org/licenses/by/4.0/

(c) (i) Open Access

\begin{abstract}
Gamma radiation exposure and physical inactivity occur in medical radiotherapy patients and astronauts resulting in substantial deterioration of their health. At the molecular level, the radiation triggers elevated markers for DNA double-strand breaks and tumorigenicity. Cell stasis is a potential phenomenon associated with low physical activity in recovering cancer patients and astronauts. This preliminary study assessed parameters of stasis and gamma radiation on human adipose stem cells (ADSCs) that have important regenerative functions for the body. A prototype pharmaceutical formulation (PF) was tested to prevent and reverse the effects of radiation and stasis. ADSCs were subjected to short-term ( 1 - 5 days) and longer-term ( 8 - 25 days) stasis and radiation with a combined total exposure of alpha, beta and gamma radiation measured at $455 \mathrm{microSv} / \mathrm{hr}$ on the Geiger counter. Cell health markers were grouped for characteristics of cellular health (annexin, H2A.X, NO, ROS) and tumorigenicity potential (P13, Ki67, MAPK) that were measured with flow cytometry. Results showed PF to improve cell health in days $1-5$ compared to stasis $(\mathrm{p}=0.01)$ and radiation $(\mathrm{p}=0.02)$, and PF reduced tumorigenicity compared with stasis $(p=0.018)$ and radiation $(p=0.03)$. For longer exposure ( 8 - 25 days) PF improved cellular health compared with stasis $(\mathrm{p}=0.038)$ and showed a non-significant trend for decreasing radiation effects $(p=0.07)$. There was decreased tumorigenicity compared with stasis
\end{abstract}


$(\mathrm{p}=0.003)$ and radiation $(\mathrm{p}=0.005)$. This preliminary evaluation of the PF showed it to have $88 \%(66 / 75)$ positive assay results $(\mathrm{p}<0.00001$ Chi-square) indicating three promising beneficial effects: 1) prevent cell/DNA damage, 2) reduce cancer risk, and 3) recover damaged and precancerous stem cells. The PF could have important applications for medical radiotherapy patients, astronauts and future space mining personnel. PF reduced carcinogenesis and DNA damage of stem cells by approximately $50 \%$ from radiation that was the microSievert equivalent of 4 months on board the International Space Station.

\section{Keywords}

Astronauts, DNA, Gamma Radiation, Radiotherapy, Space Medicine, Space Mining, Anti-Aging, Stem Cells

\section{Introduction}

Gamma radiation exposure and reduced physical activity occur in cancer patients and the elite occupation of astronauts. Gamma radiation has important therapeutic applications in the management of cancer. However, this form of radiation has strong ionization potential to initiate harmful molecular and cellular effects to adjacent healthy tissues during radiotherapy by triggering secondary tumors and fibrosis [1]. Medical radiation personnel also are at greater risk of developing cancer [2]. Other "at risk" occupations are astronauts where cosmic radiation of high energy alpha particles and gamma radiation causes extensive medical problems during space missions [3]. It is a major occupational hazard for these highly trained personnel and declining astronaut health is a major limitation to interplanetary manned missions and space mining operations. The generally accepted maximum life-time on board the International Space Station is six months due to accumulated gamma radiation doses.

At the cellular level gamma radiation promotes DNA degradation, cell stress and tumorigenicity (tumor progression and cancer). Established markers for the upregulation of these events include annexin, H2A.X, P13, Ki67 and MAPK [4] [5] [6] [7] that can be measured by flow cytometry. Significant numbers of affected differentiated cells regress with general degeneration of tissues and organs at the macroscopic level [8]. In essence, the physical body undergoes rapid aging. The regenerative phase to repair damaged tissue is critically dependent on stem cells [9]. There is a lack of adequate research on the effects of gamma radiation to stem cells. Increased knowledge in this field would lead to improved outcomes and survival rates for radiation personnel, radiotherapy patients and astronauts. In addition to gamma radiation exposure, the environment of recovering cancer patients and astronauts is one of substantially decreased physical activity (stasis). In contrast, strenuous physical activity is known to increase the regenerative mechanisms of the body by increasing circulating stem cells. The 
analysis of stem cell health from radiation and stasis in a laboratory model could assist in determining the relative contributions of these variables for treating patients and for developing space medicine radiation guidelines. A recent study has shown the effect on DNA from brief episodes of microgravity [10].

The purpose of this study was to develop a simplified and compact laboratory method to identify the effects of ionizing radiation and inactivity (stasis) on human adipose stem cells to better understand these variables of the space environment. A further objective was to undertake a preliminary evaluation of a pharmaceutical formulation (PF) for the prevention and recovery of stem cells exposed to radiation and stasis.

\section{Methods}

\section{Subjects}

Adipose derived stem cells (ADSCs) were obtained from human abdominal fat after standard tumescent liposuction by a surgeon. The lipoaspirate underwent mechanical emulsification, high speed vortex mixing and centrifugation to yield the stem cell enriched stromal vascular fraction (SVF). The method has been previously reported in detail by the author [11]. The SVF for this study was obtained from six subjects comprising of two males and four females age range 32 - 50 years (mean 43.3 years, SD 8). Four of the subjects worked in an office environment, one subject reported regular physical work in the manufacturing industry and one subject reported a 10 year history as a professional athlete. The clinical use of the SVF was for administration to treat neuropathic pain in the majority of subjects. Parameters of cell health from a sample of the SVF are conducted as part of the laboratory validation protocol. The SVFs of three additional subjects (female 45 years office worker, female 67 years and male 72 years retired) were used in the development of the antiradiation PF ( $n=499$ assays). These subjects were not used in the irradiation study.

\section{Instrumentation and validation}

Parameters of cell health of the ADSCs were determined by a Muse Cell Analyzer (EMD Millipore Corp. Hayward CA). The optics of the Muse has a single $532 \mathrm{~nm}$ green laser excitation, forward scatter detector and two fluorescence detectors (YLW 576/28, RED 680/30). The software has multiple parameters for analyzing cell health. Each parameter has default axes that are preset for best fit and can be manually adjusted by the operator for optimizing the data plots. Specific Merck Millipore reagent kits are typically used for each parameter for identification of discrete cell populations. For example, the Muse ${ }^{\varpi}$ Annexin V \& Dead Cell Kit uses a single reagent and two stains to reliably stain and differentiate live, dead, early and late apoptotic cells. Without reagents the Muse still provides useful profiling as the instrument employs relative fluorescence but with a reduction in the rigorous discriminatory cell profiles. This screening study was conducted without reagents to avoid any potential chemical reactions between reagents and the developed PF. Methylene blue stained SVF and 1000× oil mi- 
croscopy was used for stem cell identification that is also part of laboratory validation. Four sample runs of SVF in two subjects $(n=10$ repeats of each run measuring annexin live cells) showed the Muse to have excellent repeatability and precision (CV 1\%). The active PF in a saline control (without SVF) was subjected to the cytometer and showed background fluorophore intensity was $<0.1 \%$. Tests were conducted for annexin (apoptosis profile), H2A.X (DNA single/double-strand breaks), P13 (increased tumor potential), Ki67 (increased mitosis), MAPK (cell stress), nitric oxide (NO) (inflammatory mediator from stressful stimuli) and reactive oxygen species (ROS) (progression of inflammation). Additional apoptosis markers of BCL-2 and caspase-3/7 were performed in some samples. For statistical analyses the markers were grouped for characteristics of cellular health (annexin, H2A.X, NO, ROS, BCL-2, caspase 3/7) and tumorigenicity potential (P13, Ki67, MAPK). Gel electrophoresis of the DNA was not performed in this preliminary study.

\section{Radiation}

Radiation to the SVF was obtained by placing $2 \mathrm{~mL}$ Eppendorf tubes with the SVF directly on the radioactive mineral torbernite (Australian mining location) comprising of a large specimen $71 \mathrm{gm}$ and four smaller specimens with a combined mass of $27 \mathrm{gm}$. Radiation intensity was measured by two Geiger counters. The first counter (GMC-300E Plus, GQ Electronics, Seattle WA, USA) measured $281.1 \mathrm{microSieverts/hour} \mathrm{(microSv/hr)} \mathrm{from} \mathrm{the} 71 \mathrm{gm}$ specimen and $174.1 \mathrm{mi}-$ croSv/hr from the combined four smaller specimens. The detection tube was parallel to the torbernite and situated $3 \mathrm{~mm}$ from the mineral to yield a total "effective radiation dose" of $455.2 \mathrm{microSv} / \mathrm{hr}$ (11 milliSv/day) to the SVF (Figure 1). The second Geiger counter (CEM DT-9501 CEM Instruments, Shenzen Everbest Machinery Industry Co. Ltd. Shenzen, PR China) has a collimated vertical detector placed $13 \mathrm{~mm}$ from the torbernite and gave separate measurements for alpha, beta and gamma radiation. The $71 \mathrm{gm}$ specimen had a ratio of gamma $31 \%$, beta $31 \%$, alpha $38 \%$; the combined four smaller specimens measured gamma
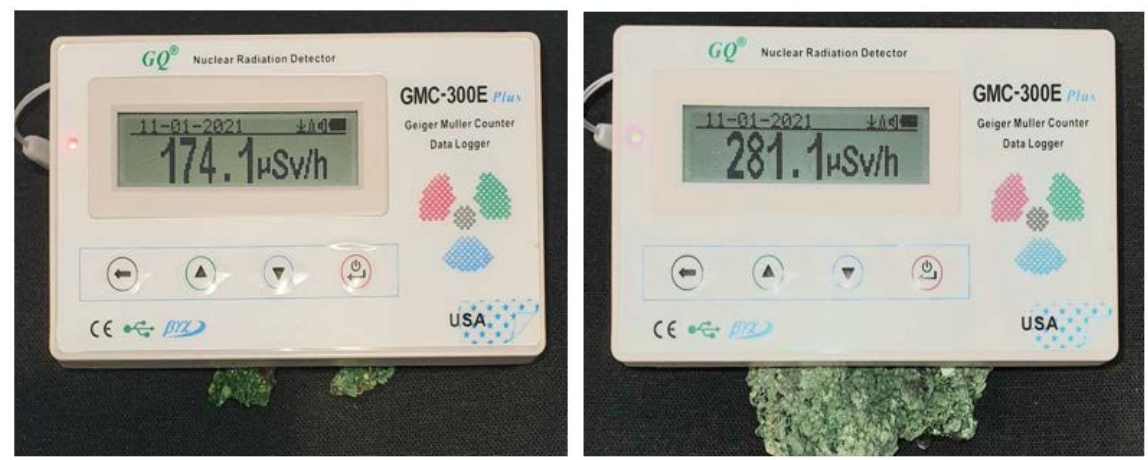

Figure 1. Total radiation output from torbernite shows the large $71 \mathrm{gm}$ specimen to have radiation of $281 \mathrm{microSv} / \mathrm{hr}$ and the combined output of the four smaller pieces with a total mass of $27 \mathrm{gm}$ showing $174 \mathrm{microSv} / \mathrm{hr}$. The stem cells were placed in $2 \mathrm{~mL}$ Eppendorf tubes and sandwiched between the specimens giving a potential total radiation exposure of $455 \mathrm{microSv} / \mathrm{hr}$. 
$32 \%$, beta $58 \%$ and alpha $10 \%$ radiation. The SVF tubes were packed between all specimens giving an estimated total radiation dose to the stem cells of $140 \mathrm{mi}$ croSv/hr of gamma radiation (3.4 milliSv/day), $187 \mathrm{microSv} / \mathrm{hr}$ of beta radiation and $127 \mathrm{microSv} / \mathrm{hr}$ of alpha radiation. Astronauts on board the International Space Station (ISS) are exposed to $400 \mathrm{microSv} /$ day (150 milliSv per year). A general estimate for this study was five days of SVF exposure on torbernite approximated four months on board the ISS, or five consecutive CT examinations in five days.

\section{Study design}

In this screening study SVF samples were carefully allocated to assess a spectrum of cell health assays. Samples were divided into control and active exposure vials. However, limited SVF volumes only permitted single measurements for each data point. Partitioned data sets on affected cell health variables were combined, for example, annexin cell plot distributions of early apoptosis, late apoptosis and dead cells were pooled for statistical analyses. Statistical tests used paired t test, Welch's t test, and Chi-square test.

Two studies were performed on the SVFs:

1) Freshly acquired SVF stem cells were immediately assayed for five days at 37C and divided into control cells in stasis, gamma irradiated cells in stasis, and irradiated cells in stasis with the addition of the test PF. Baseline measurements were recorded from freshly acquired SVFs from four subjects.

2) SVF left in stasis for a prolonged period (8 - 25 days) then divided into control cells in stasis, gamma irradiated cells in stasis, and irradiated cells in stasis with the test PF.

\section{Prototype pharmaceutical formulation}

The PF was based on several known compounds including quercetin, coenzyme Q10 and other analytes that have been shown to attenuate cellular inflammation and H2A.X [12] [13]. To this base the author added a specific mix of additional natural bioactives including plant polyphenols. Bioactives were obtained from the raw plant materials typically by liquid/liquid solvent extractions of distilled water, ethanol/methanol and dimethyl sulfoxide according to the solubility profiles of the individual analytes. The PF was soluble in normal saline and was pipetted into the SVF. Confirmation of analyte purity was conducted by a photodiode array detector attached to high performance liquid chromatography (LC) and molecular identity confirmed by a single quadrupole mass spectrometer (MS) with an electrospray interface (LC-MS 2020 system, Shimadzu Corp. Kyoto, Japan). The chromatographic parameters for the LC: mobile phase A $0.1 \%$ acetic acid in MilliQ water, B acetonitrile, $0.2 \mathrm{~mL} / \mathrm{min}$ binary gradient $5 \%$ $60 \%$ B over 45 minutes with a C8 $2.1 \mathrm{~mm}$ diameter $\times 150 \mathrm{~mm}$ long Vydac column (Grace Corp., Columbia, MD, USA). The parameters for the MS were nitrogen flow $1.5 \mathrm{~L} / \mathrm{min}$ and block heater at 200C. Quercetin (molecular weight 302.2) is shown as an example for establishing the purity and confirmation of molecular identity of the analytes in the PF (Figure 2). 

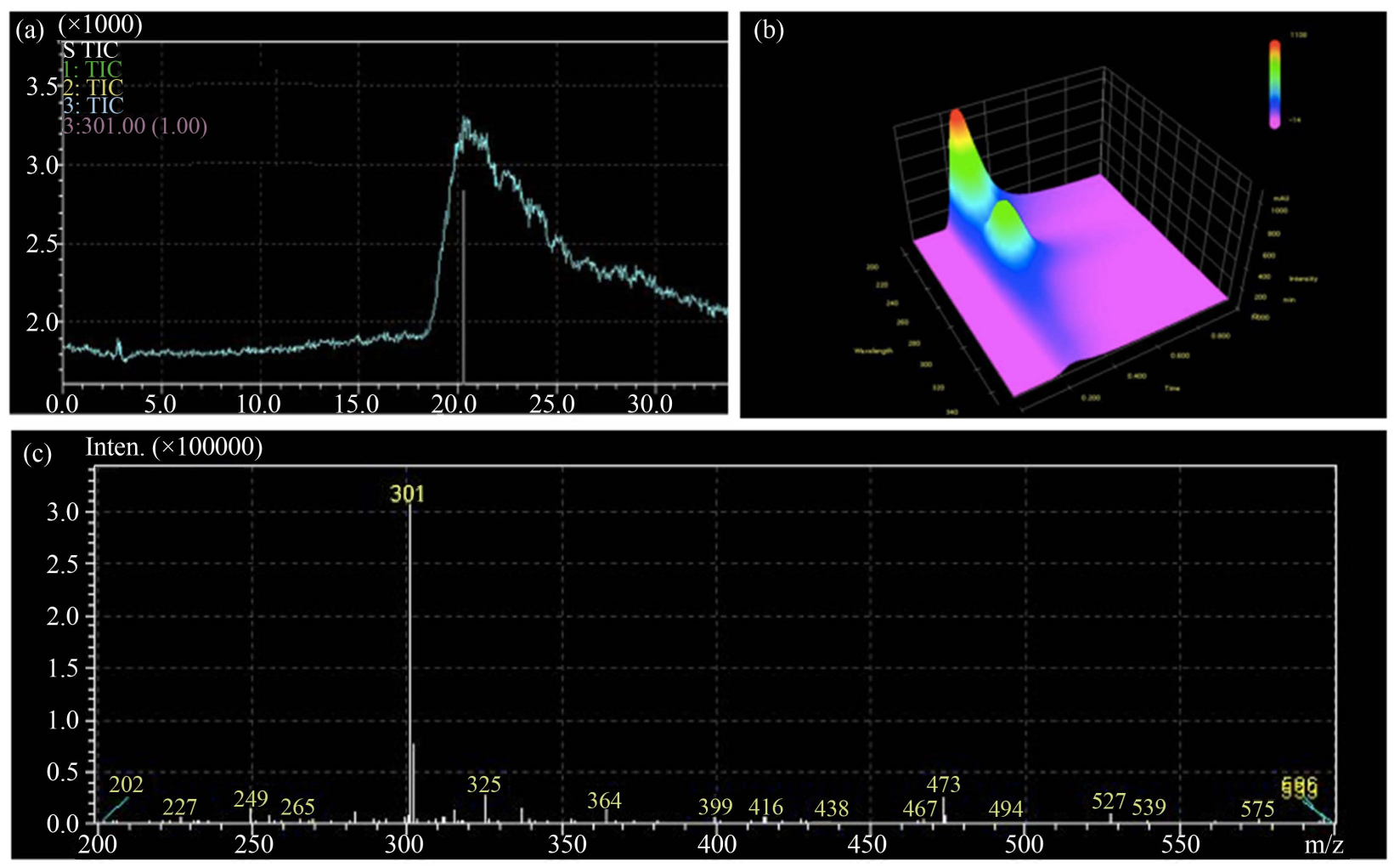

Figure 2. Method development for establishing purity and confirmation of the molecular identity of the bioactive agents in the pharmaceutical formulation. Analysis used high performance liquid chromatography coupled to a mass spectrometer (LCMS) with an electrospray interface. Quercetin (molecular weight 302) is used as an example of one of the bioactives. (a) LCMS with single ion monitoring at 301 shows a retention time of quercetin at 20.3 minutes in the final pharmaceutical formulation, (b) UV scans 190 - $800 \mathrm{~nm}$ showed peak purity of quercetin with primary peak absorbance at $190 \mathrm{~nm}$ and secondary peak at $220 \mathrm{~nm}$, (c) negative scanning mode (m/z range $200-600)$ of the mass spectrometer shows $\mathrm{m} / \mathrm{z} 301$ to confirm identity of the quercetin.

\section{Results}

There was a total of 480 SVF assays conducted in the two studies (study 1, Table 1; study 2, Table 2). Cell health and DNA damage markers (annexin, H2A.X, DNA damage, NO, ROS) were grouped for comparing the control SVF in stasis (C), gamma irradiated SVF (G) and irradiated SVF with the pharmaceutical formulation (PF). Pooled mean values showed significant improvement for cell health by the PF days $1-5$ for $C$ versus PF $(p=0.01)$ and $G$ versus PF $(p=0.02)$. For the days 8 - 25 there was a significant improvement of $\mathrm{PF}$ compared with $\mathrm{C}$ $(\mathrm{p}=0.042)$ and a non-significant trend with G (0.07) (Figure 3). Tumor progression markers used pooled mean scores of P13, EGFR, Ki67, MAPK and BCL-2. For days $1-5$ the PF reduced tumorigenicity compared with $\mathrm{C}$ ( $\mathrm{p}=$ 0.018 ) and radiation ( $\mathrm{p}=0.03$ ). For days 8 - $25 \mathrm{PF}$ reduced tumorigenicity compared with $\mathrm{C}(\mathrm{p}=0.003)$ and radiation $(\mathrm{p}=0.005)$ (Figure 4$)$.

There were $66 / 75(88 \%)$ positive assay results that showed the PF to recover damaged cells and reduce tumorigenicity (Chi-square $\mathrm{p}<0.00001)$ (Figure 5). There was a significant deterioration of the cell health $(p=0.002)$ and increased tumor markers ( $\mathrm{p}=0.001$, Welch's t test) between the SVF study 1 interval of 1 5 days and study 2 interval of 8 - 25 days (Table 3 ). 
Table 1. The SVF raw data from study 1 (Days 1 - 5) of four subjects. SVFs were compared over five days at 37C incubation. Legend: S\# (subject \#), d (day/s), B (baseline SVF, day 0), C (control SVF in stasis), G (gamma irradiated SVF in stasis), PF (gamma irradiated SVF with active PF in stasis), annexin (annexin V), DNA-X (multicolor DNA damage), ROS (reactive oxygen species), NO (nitric oxide). Percentage values given for positive markers of annexin, H2A.X, P13, Ki67, MAPK, DNA-X, ROS, NO. Live cells measured on the annexin parameter and are expressed as $\mathrm{n} \times 10^{6}$ live cells $/ \mathrm{ml}$. Results showed PF to improve cell health in days 1 - 5 compared to stasis $(\mathrm{p}=0.01)$ and radiation $(\mathrm{p}=0.02)$, and PF reduced tumorigenicity compared with stasis $(\mathrm{p}=0.018)$ and radiation $(\mathrm{p}=0.03)$.

\begin{tabular}{|c|c|c|c|c|c|c|c|c|c|}
\hline Subject & Annexin & H2A.X & DNA-X & ROS & NO & Live cells & P13 & Ki67 & MAPK \\
\hline S\#1 B & $0 \%$ & $0.1 \%$ & $0 \%$ & $0 \%$ & $0.1 \%$ & 5.92 & $0 \%$ & $0 \%$ & $0 \%$ \\
\hline $\mathrm{C} 1 \mathrm{~d}$ & $7.2 \%$ & $7.6 \%$ & $0.2 \%$ & $0 \%$ & $0.9 \%$ & 2.71 & $0.1 \%$ & $0.4 \%$ & $0.2 \%$ \\
\hline $3 \mathrm{~d}$ & $44 \%$ & $46.9 \%$ & $23.9 \%$ & $0 \%$ & $18.2 \%$ & 0.80 & $11.4 \%$ & $3.6 \%$ & $4.7 \%$ \\
\hline $5 \mathrm{~d}$ & $10 \%$ & $18.2 \%$ & $2.9 \%$ & $0 \%$ & $3.66 \%$ & 0.36 & $2.4 \%$ & $0.6 \%$ & $0.9 \%$ \\
\hline $\mathrm{G} 1 \mathrm{~d}$ & $5.6 \%$ & $7.4 \%$ & $0.5 \%$ & $0 \%$ & $1.4 \%$ & 3.06 & $1.0 \%$ & $0.4 \%$ & $0.3 \%$ \\
\hline $3 \mathrm{~d}$ & $36.4 \%$ & $39.7 \%$ & $15 \%$ & $0.1 \%$ & $10.5 \%$ & 1.13 & $5.5 \%$ & $1.8 \%$ & $3.8 \%$ \\
\hline $5 \mathrm{~d}$ & $18.8 \%$ & $8.4 \%$ & $1.3 \%$ & $0 \%$ & $1.4 \%$ & 0.60 & $0.7 \%$ & $0.2 \%$ & $0.1 \%$ \\
\hline PF $1 \mathrm{~d}$ & $18.2 \%$ & $16.28 \%$ & $2.8 \%$ & $0 \%$ & $2.8 \%$ & 2.76 & $1.9 \%$ & $1.4 \%$ & $0.4 \%$ \\
\hline $3 \mathrm{~d}$ & $14.7 \%$ & $11.2 \%$ & $1.4 \%$ & $0 \%$ & $3 \%$ & 2.52 & $1.1 \%$ & $0.4 \%$ & $0.1 \%$ \\
\hline $5 \mathrm{~d}$ & $6.1 \%$ & $7.4 \%$ & $1.9 \%$ & $0 \%$ & $1.2 \%$ & 2.83 & $0.7 \%$ & $0.4 \%$ & $0 \%$ \\
\hline S\#2 B & $6.9 \%$ & $0.8 \%$ & $0.1 \%$ & $0 \%$ & $0.2 \%$ & 2.26 & $0.2 \%$ & $0.1 \%$ & $0 \%$ \\
\hline $\mathrm{C} 1 \mathrm{~d}$ & $1.9 \%$ & $3.0 \%$ & $0.7 \%$ & $0 \%$ & $0.4 \%$ & 1.10 & $0.3 \%$ & $0.1 \%$ & $0.2 \%$ \\
\hline $3 \mathrm{~d}$ & $3 \%$ & $1.4 \%$ & $2.5 \%$ & $0.1 \%$ & $1 \%$ & 1.36 & $0.4 \%$ & $0.4 \%$ & $0.3 \%$ \\
\hline $5 \mathrm{~d}$ & $4.8 \%$ & $1.8 \%$ & $0.4 \%$ & $0.1 \%$ & $0.6 \%$ & 1.20 & $0.6 \%$ & $0.2 \%$ & $0.7 \%$ \\
\hline $\mathrm{G} 1 \mathrm{~d}$ & $2.5 \%$ & $3.6 \%$ & $0.9 \%$ & $0 \%$ & $1.3 \%$ & 0.84 & $0.1 \%$ & $0.2 \%$ & $0.1 \%$ \\
\hline $3 \mathrm{~d}$ & $3.2 \%$ & $1.7 \%$ & $1.8 \%$ & $0.1 \%$ & $0.6 \%$ & 1.39 & $0.2 \%$ & $0.4 \%$ & $0.2 \%$ \\
\hline $5 \mathrm{~d}$ & $4.5 \%$ & $6.9 \%$ & $1 \%$ & $0 \%$ & $0.8 \%$ & 1.34 & $0.8 \%$ & $0.2 \%$ & $0.7 \%$ \\
\hline PF $1 \mathrm{~d}$ & $6.4 \%$ & $7.7 \%$ & $7.1 \%$ & $0 \%$ & $0.7 \%$ & 0.24 & $0.91 \%$ & $0.4 \%$ & $0.3 \%$ \\
\hline $3 \mathrm{~d}$ & $7.5 \%$ & $6.2 \%$ & $2.8 \%$ & $0 \%$ & $1.1 \%$ & 0.26 & $0.34 \%$ & $0.5 \%$ & $0.3 \%$ \\
\hline $5 \mathrm{~d}$ & $5.5 \%$ & $7.8 \%$ & $2.7 \%$ & $0 \%$ & $3.4 \%$ & 0.26 & $0.4 \%$ & $0.4 \%$ & $0.2 \%$ \\
\hline S\#3 B & $0.4 \%$ & $12.2 \%$ & $2.5 \%$ & $0 \%$ & $1.8 \%$ & 2.00 & $1.6 \%$ & $1 \%$ & $1.2 \%$ \\
\hline $\mathrm{C} 1 \mathrm{~d}$ & $3.7 \%$ & $0.9 \%$ & $0.2 \%$ & $0 \%$ & $0.5 \%$ & 3.46 & $0.4 \%$ & $0 \%$ & $0.1 \%$ \\
\hline $3 \mathrm{~d}$ & $4.3 \%$ & $1.6 \%$ & $1.2 \%$ & $0 \%$ & $0.5 \%$ & 3.70 & $0.2 \%$ & $0.0 \%$ & $0.3 \%$ \\
\hline $5 \mathrm{~d}$ & $2.9 \%$ & $3.7 \%$ & $0.2 \%$ & $0 \%$ & $0.6 \%$ & 3.44 & $0.6 \%$ & $0.1 \%$ & $0.7 \%$ \\
\hline $\mathrm{G} 1 \mathrm{~d}$ & $4.5 \%$ & $1.4 \%$ & $0.5 \%$ & $0 \%$ & $0.7 \%$ & 3.33 & $0.2 \%$ & $0.3 \%$ & $0.1 \%$ \\
\hline $3 \mathrm{~d}$ & $3.5 \%$ & $1.8 \%$ & $1.1 \%$ & $0.2 \%$ & $0.3 \%$ & 3.61 & $0.5 \%$ & $0.1 \%$ & $0.1 \%$ \\
\hline $5 \mathrm{~d}$ & $2.9 \%$ & $2 \%$ & $0.2 \%$ & $0 \%$ & $0.7 \%$ & 3.52 & $0.3 \%$ & $0 \%$ & $0.4 \%$ \\
\hline PF $1 \mathrm{~d}$ & $8.4 \%$ & $8.2 \%$ & $2 \%$ & $0 \%$ & $1.2 \%$ & 0.84 & $0.8 \%$ & $0.3 \%$ & $0.4 \%$ \\
\hline $3 \mathrm{~d}$ & $5.2 \%$ & $8 \%$ & $0.7 \%$ & $0 \%$ & $1 \%$ & 0.86 & $0.2 \%$ & $0.2 \%$ & $0.1 \%$ \\
\hline $5 \mathrm{~d}$ & $3.7 \%$ & $5.6 \%$ & $1.3 \%$ & $0 \%$ & $0.6 \%$ & 0.85 & $0.5 \%$ & $0.5 \%$ & $0.1 \%$ \\
\hline S\#4 B & $0.9 \%$ & $0.5 \%$ & $0 \%$ & $0 \%$ & $0.1 \%$ & 1.98 & $0.2 \%$ & $0.1 \%$ & $0 \%$ \\
\hline $\mathrm{C} 1 \mathrm{~d}$ & $19.5 \%$ & $47.4 \%$ & $18.0 \%$ & $0.2 \%$ & $12.9 \%$ & 0.53 & $9.0 \%$ & $3.9 \%$ & $3.3 \%$ \\
\hline
\end{tabular}


Continued

\begin{tabular}{|c|c|c|c|c|c|c|c|c|c|}
\hline $3 \mathrm{~d}$ & $14.9 \%$ & $17.8 \%$ & $4.7 \%$ & $0 \%$ & $3.5 \%$ & 0.42 & $2.4 \%$ & $1.6 \%$ & $0.6 \%$ \\
\hline $5 \mathrm{~d}$ & $2.7 \%$ & $3.7 \%$ & $2.1 \%$ & $0 \%$ & $1.5 \%$ & 0.50 & $0.8 \%$ & $0.1 \%$ & $0.4 \%$ \\
\hline $\mathrm{G} 1 \mathrm{~d}$ & $23.7 \%$ & $50.6 \%$ & $9.7 \%$ & $0.1 \%$ & $16.2 \%$ & 0.34 & $11.7 \%$ & $4.4 \%$ & $3.7 \%$ \\
\hline $3 \mathrm{~d}$ & $11.3 \%$ & $18.3 \%$ & $4 \%$ & $0 \%$ & $2.8 \%$ & 0.58 & $2.5 \%$ & $1.4 \%$ & $0.7 \%$ \\
\hline $5 \mathrm{~d}$ & $3.2 \%$ & $11 \%$ & $1.5 \%$ & $0.1 \%$ & $2.5 \%$ & 0.92 & $0.6 \%$ & $0.4 \%$ & $1.2 \%$ \\
\hline PF $1 \mathrm{~d}$ & $6.2 \%$ & $8.8 \%$ & $1.6 \%$ & $0.1 \%$ & $2.3 \%$ & 1.07 & $0.5 \%$ & $0.4 \%$ & $0.3 \%$ \\
\hline $3 \mathrm{~d}$ & $5.8 \%$ & $4.8 \%$ & $2.7 \%$ & $0 \%$ & $0.9 \%$ & 1.39 & $0.3 \%$ & $0 \%$ & $0 \%$ \\
\hline $5 \mathrm{~d}$ & $2.9 \%$ & $7.1 \%$ & $1.6 \%$ & $0 \%$ & $0.7 \%$ & 1.51 & $0.7 \%$ & $0 \%$ & $0.1 \%$ \\
\hline
\end{tabular}

Table 2. Raw data from study 2 for analysis of markers from Days 8 - 25 in three subjects (\#1, \#5, \#6). Subject \#1 SVF left for 13 days at 20C, then radiation for five days with aliquots of control, radiation and radiation with PF, analyzed at day 13 and day 18 . Subject \#5 SVF left for 20 days at 20C, then radiation for five days with aliquots of control, radiation and radiation with PF, analyzed at day 20 and day 25. Subject \#6 with SVF left in stasis for eight days at 37C, then radiation for six days with three aliquots of control, radiation and radiation with PF, analyzed at day 8, day 11 and day 14. Legend: S\# (subject \#), d (day/s), SVF (stromal vascular fraction), B (baseline SVF, day 0), C (control SVF in stasis), G (gamma irradiated SVF in stasis), PF (gamma irradiated SVF with active PF in stasis, C-A (control with active PF in stasis), G-A (gamma irradiated SVF with active PF in stasis). Parameter markers: annexin (annexin V), DNA-X (multicolor DNA damage), ROS (reactive oxygen species), NO (nitric oxide). Percentage values given for positive markers of annexin, H2A.X, P13, Ki67, MAPK, DNA-X, ROS, NO, BCL-2. Live cells measured on the annexin parameter and are expressed as $\mathrm{n} \times 10^{6}$ live cells $/ \mathrm{ml}$. When cell health parameters of annexin, H2A.X, DNA damage, ROS, NO and live cells were pooled there was a significant difference between Control and PF $(\mathrm{p}=0.038)$ and a non-significant trend of radiation compared with PF $(\mathrm{p}=0.07)$. There were significant results for PF to reduce tumorigenicity compared with stasis $(\mathrm{p}=0.003)$ and gamma radiation $(\mathrm{p}=0.005)$ from pooled values of P13, EGFR, Ki67, MAPK and BCL-2 in subjects \#1, \#5, \#6. There were $66 / 75$ positive assay results that showed $P F$ to recover damaged cells, reduce tumorigenicity and increase the regenerative potential by an increased number of stem cells (Chi-square $\mathrm{p}<0.00001$ ).

\begin{tabular}{|c|c|c|c|c|c|c|c|c|c|c|c|}
\hline Subject & Annexin & H2A.X & DNA-X & ROS & NO & Live cells & P13 & EGFR & Ki67 & MAPK & BCL-2 \\
\hline S\#1 B $13 \mathrm{~d}$ & $25 \%$ & $29 \%$ & $14.8 \%$ & $0.6 \%$ & $4.2 \%$ & 0.11 & $8 \%$ & $5.3 \%$ & $3.8 \%$ & $4.8 \%$ & $2.5 \%$ \\
\hline C $18 \mathrm{~d}$ & $23.3 \%$ & $33.6 \%$ & $10.5 \%$ & $0 \%$ & $4.9 \%$ & 0.22 & $6 \%$ & $4.4 \%$ & $2.7 \%$ & $3.4 \%$ & $1.1 \%$ \\
\hline C-PF $18 \mathrm{~d}$ & $12.2 \%$ & $17.5 \%$ & $10.5 \%$ & $0.1 \%$ & $4.1 \%$ & 0.48 & $3.1 \%$ & $2 \%$ & $2 \%$ & $2 \%$ & $0.4 \%$ \\
\hline $\mathrm{G} 18 \mathrm{~d}$ & $30.3 \%$ & $48.3 \%$ & $10.7 \%$ & $0 \%$ & $12.7 \%$ & 0.08 & $6.3 \%$ & $3.4 \%$ & $5.3 \%$ & $8.9 \%$ & $5.2 \%$ \\
\hline G-PF $18 \mathrm{~d}$ & $2.7 \%$ & $17 \%$ & $13.9 \%$ & $0.3 \%$ & $9.6 \%$ & 0.25 & $1 \%$ & $0.8 \%$ & $1.8 \%$ & $1.3 \%$ & $3.1 \%$ \\
\hline S\#5 B $20 \mathrm{~d}$ & $8.4 \%$ & $11.9 \%$ & $5.6 \%$ & $0.1 \%$ & $2.8 \%$ & 0.11 & $3.8 \%$ & $2.4 \%$ & $2.8 \%$ & $1.6 \%$ & $1.9 \%$ \\
\hline C $25 \mathrm{~d}$ & $6.2 \%$ & $24.5 \%$ & $20.9 \%$ & $0.2 \%$ & $12.6 \%$ & 0.09 & $5.1 \%$ & $2 \%$ & $3.3 \%$ & $9.7 \%$ & $7.2 \%$ \\
\hline C-PF $25 \mathrm{~d}$ & $1.8 \%$ & $14.9 \%$ & $16.4 \%$ & $0.1 \%$ & $1.3 \%$ & 0.21 & $0.8 \%$ & $0.5 \%$ & $1.1 \%$ & $2 \%$ & $1.9 \%$ \\
\hline G $25 \mathrm{~d}$ & $7.2 \%$ & $37.8 \%$ & $27.3 \%$ & $0.6 \%$ & $14.6 \%$ & 0.15 & $7.6 \%$ & $4.2 \%$ & $2.1 \%$ & $7.1 \%$ & $4.9 \%$ \\
\hline G-PF $25 \mathrm{~d}$ & $3.8 \%$ & $29.4 \%$ & $29.8 \%$ & $0 \%$ & $9.6 \%$ & 0.18 & $5.4 \%$ & $1.2 \%$ & $1.9 \%$ & $4.2 \%$ & $1.8 \%$ \\
\hline S\#6 B $8 \mathrm{~d}$ & $27 \%$ & $59.2 \%$ & & & & 0.23 & $11.6 \%$ & $0.9 \%$ & & & \\
\hline C $11 \mathrm{~d}$ & $40.1 \%$ & $81.4 \%$ & & & & 0.19 & $16.2 \%$ & $5.8 \%$ & & & \\
\hline $\mathrm{G} 11 \mathrm{~d}$ & $43.1 \%$ & $81.3 \%$ & & & & 0.09 & $21.5 \%$ & $8.8 \%$ & & & \\
\hline G-PF $11 \mathrm{~d}$ & $44 \%$ & $40.7 \%$ & & & & 0.27 & $2.8 \%$ & $2 \%$ & & & \\
\hline C $14 \mathrm{~d}$ & $57.6 \%$ & $75.6 \%$ & & & & 0.08 & $25.5 \%$ & $17.4 \%$ & & & \\
\hline $\mathrm{G} 14 \mathrm{~d}$ & $72.3 \%$ & $89.5 \%$ & & & & 0.05 & $34.4 \%$ & $19.2 \%$ & & & \\
\hline G-PF $14 \mathrm{~d}$ & $24.6 \%$ & $36.1 \%$ & & & & 0.22 & $5.5 \%$ & $3.7 \%$ & & & \\
\hline
\end{tabular}




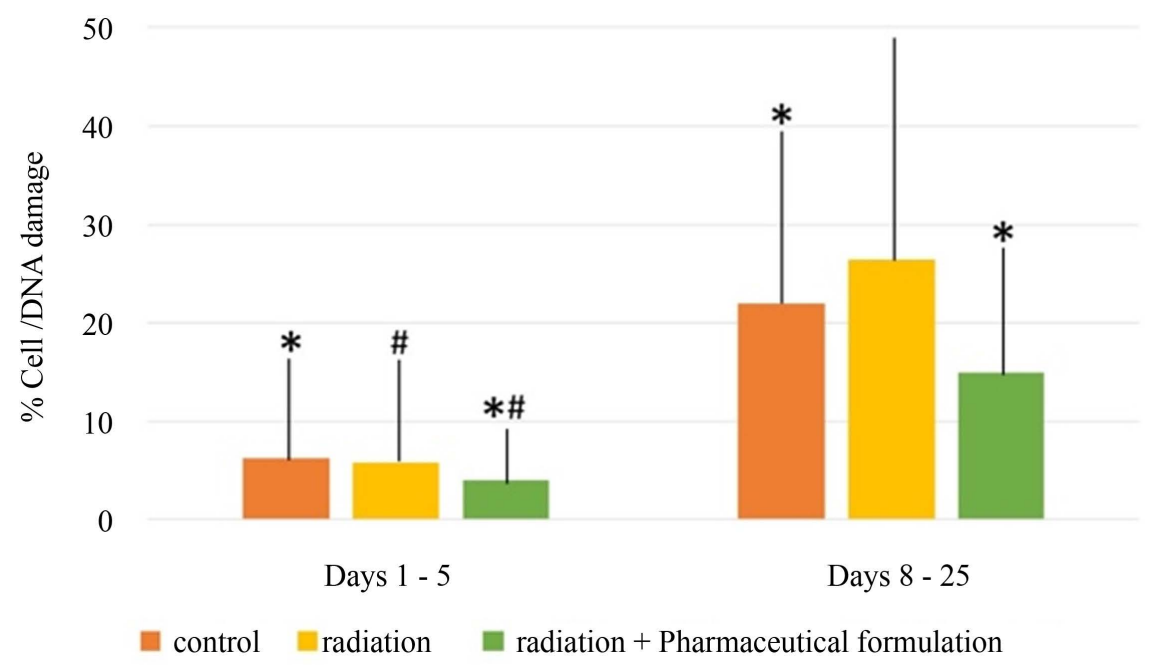

Figure 3. Pooled mean (SD) values of cell health for the SVF at 37C over the time intervals of days 1 - 5 and days 8 - 25 comparing control SVF in stasis (C), irradiated SVF (G) and the irradiated SVF with PF (PF). Markers were grouped for characteristics of cellular health (annexin, H2A.X, DNA damage, NO, ROS). There were significant differences $\left({ }^{*}\right.$ \# $p<0.05)$ for cell health from mean values in days $1-5 \mathrm{C}$ versus PF $(p=0.01)$ and G versus PF $(\mathrm{p}=0.02)$. For the days $8-25$ day interval there was a significant differences for cell health between $C$ versus $P F(p=0.038)$ and a non-significant trend of $G$ versus $P F$ (0.07).

Table 3. Summary of grouped parameters for all subjects from day 1 to day 25 . Results are shown as mean values (SD) for cell health and tumorigenicity. SD values were high due to the limited sample size. Markers were grouped for characteristics of cellular health (annexin, H2A.X, NO, ROS, live cells $1 \times 10^{6}$ ) and tumorigenicity potential (P13, EGFR, Ki67, MAPK, BCL-2). There was a significant deterioration of the cell health $(\mathrm{p}=0.002)$ and increased tumor markers $(\mathrm{p}=0.001$, Welch's t-test) between the SVF study 1 interval of $1-5$ days and study 2 interval of $8-25$ days.

\begin{tabular}{|c|c|c|c|c|c|c|c|c|c|c|c|}
\hline Group & Annexin & H2A.X & DNA-X & ROS & NO & Live cells & P13 & EGFR & Ki67 & MAPK & BCL-2 \\
\hline \multirow{2}{*}{$C 1-5 d$} & $9.9 \%$ & $12.8 \%$ & $4.8 \%$ & $0.0 \%$ & $3.7 \%$ & 0.16 & $2.4 \%$ & & $0.9 \%$ & $1.0 \%$ & \\
\hline & (11.5) & $(16.4)$ & (7.5) & $(0.1)$ & (5.5) & $(0.13)$ & (3.6) & & $(1.3)$ & $(1.4)$ & \\
\hline \multirow{2}{*}{ G $1-5 d$} & $10 \%$ & $12.7 \%$ & $3.1 \%$ & $0.1 \%$ & $3.3 \%$ & 0.17 & $2.0 \%$ & & $0.8 \%$ & $1.0 \%$ & \\
\hline & $(10.3)$ & $(15.4)$ & $(4.4)$ & $(0.1)$ & $(4.7)$ & $(0.12)$ & (3.3) & & $(1.2)$ & $(1.3)$ & \\
\hline \multirow{2}{*}{ PF $1-5 d$} & $7.6 \%$ & $8.3 \%$ & $2.4 \%$ & $0.0 \%$ & $1.6 \%$ & 0.13 & $0.7 \%$ & & $0.4 \%$ & $0.2 \%$ & \\
\hline & $(4.3)$ & (2.9) & (1.6) & (0) & (1) & $(0.09)$ & $(0.4)$ & & $(0.3)$ & $(0.1)$ & \\
\hline \multirow{2}{*}{ C $8-25 d$} & $31.8 \%$ & $53.8 \%$ & $15.7 \%$ & $0.1 \%$ & $8.8 \%$ & 0.15 & $13.2 \%$ & $7.4 \%$ & $3.0 \%$ & $6.6 \%$ & $4.2 \%$ \\
\hline & $(19.1)$ & (25) & $(5.2)$ & $(0.1)$ & (3.9) & $(0.06)$ & (8.3) & $(5.9)$ & $(0.3)$ & $(3.2)$ & (3.1) \\
\hline \multirow{2}{*}{ C-PF 8 - 25 d } & $25.4 \%$ & $39.4 \%$ & $10.5 \%$ & $0.1 \%$ & $6.3 \%$ & 0.10 & $10.8 \%$ & $6.7 \%$ & $1.7 \%$ & $4.9 \%$ & $3.6 \%$ \\
\hline & (6.3) & $(14.4)$ & (5.3) & $(0)$ & $(2.5)$ & 0.04 & $(2.4)$ & $(0.7)$ & $(1.4)$ & $(1.7)$ & $(0.6)$ \\
\hline \multirow{2}{*}{ G $8-25 d$} & $34.6 \%$ & $64.2 \%$ & $19.0 \%$ & $0.3 \%$ & $13.7 \%$ & 0.09 & $17.5 \%$ & $8.9 \%$ & $3.7 \%$ & $8.0 \%$ & $5.1 \%$ \\
\hline & $(25.5)$ & $(21.7)$ & (8.3) & $(0.3)$ & $(0.9)$ & $(0.04)$ & $(11.5)$ & (6.3) & $(1.6)$ & $(0.9)$ & $(0.2)$ \\
\hline \multirow{2}{*}{ G-PF 8 - $25 d$} & $23.0 \%$ & $34.9 \%$ & $10.8 \%$ & $0.2 \%$ & $5.8 \%$ & 0.07 & $10.5 \%$ & $5.6 \%$ & $2.1 \%$ & $3.9 \%$ & $2.3 \%$ \\
\hline & $(10.3)$ & $(19.2)$ & (5.1) & $(0.1)$ & $(4.9)$ & $(0.03)$ & (5.3) & (3) & $(0.9)$ & $(2.8)$ & (2.1) \\
\hline
\end{tabular}




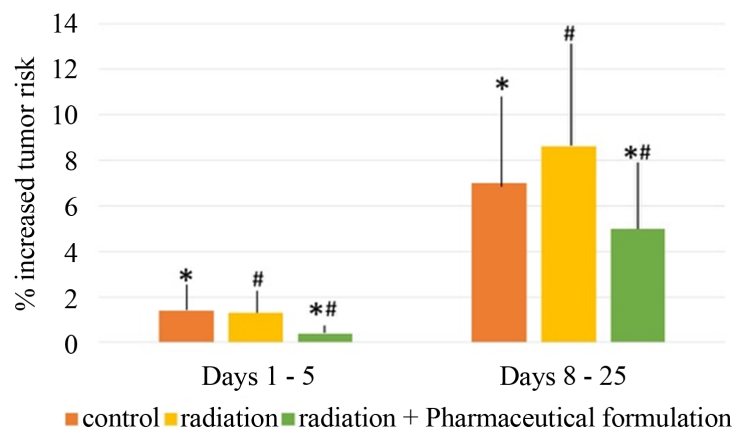

Figure 4. Pooled mean (SD) values of tumorigenicity for the SVF at $37 \mathrm{C}$ over the time intervals of days $1-5$ and days 8 - 25 comparing control SVF in stasis (C), irradiated SVF $(\mathrm{G})$ and the irradiated SVF with PF $(\mathrm{PF})\left(^{*} \# \mathrm{p}<0.05\right)$. Markers were grouped for characteristics of tumor progression using pooled values of P13, EGFR, Ki67, MAPK and BCL-2. For days $1-5$ there were significant results for PF to reduce tumorigenicity compared with stasis $(p=0.018)$ and radiation $(p=0.03)$. For days $8-25$ there were significant results for PF to reduce tumorigenicity compared with stasis $(\mathrm{p}=0.003)$ and radiation $(\mathrm{p}=$ $0.005)$.

(a1)

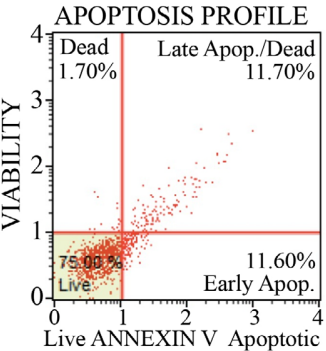

(a2)

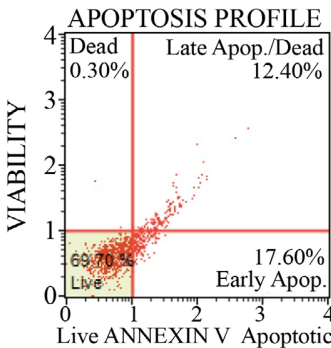

(a3)

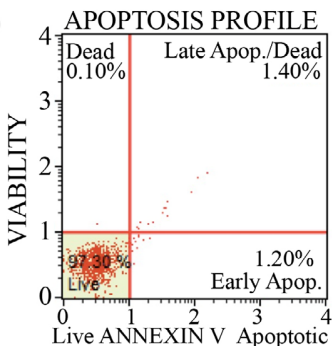

(b1)

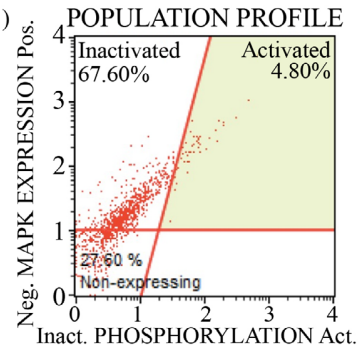

(b2)
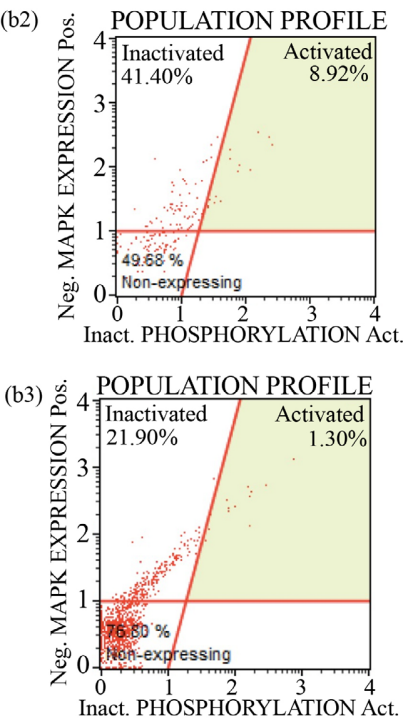

Figure 5. Sample flow cytometry assays in subject \#1 demonstrating the reduction of cell marker apoptosis, decreased tumor marker MAPK and increased live cell numbers by incubation of the stem cells in the test pharmaceutical formulation. ((a1), (b1)) baseline measurement of annexin and MAPK of the SVF left in stasis at 20C for 13 days, ((a2), (b2)) annexin and MAPK of the SVF at day 18 (after 5 days of radiation), ((a3), (b3)) annexin and MAPK of the SVF at day 18 (5 days radiation with the pharmaceutical formulation). 


\section{Discussion}

There is substantial published data on the effects from short episodes of high intensity gamma radiation to differentiated cells. Events such as very high (lethal) single radiation dose of personnel exposed to nuclear industry accidents, to the therapeutic multiple radiotherapy lower doses have been detailed. There is, however, less data on irradiated stem cells during chronic exposure that occurs to astronauts in the space environment. Stem cells underpin the regenerative potential of the damaged body. If these cells are substantially compromised this would lead to a rapid decline in astronaut health that is disastrous in space. In addition to external radiation shielding technology, the endogenous mechanisms to prevent or recover stem cell damage are suggested by the author as a priority in space exploration. Three core principles of maintaining healthy regeneration are preventing DNA breaks and enhancing repairs, increasing cell numbers to quickly regenerate the body and preventing cancer. This preliminary study had access to using limited cell numbers in assessing two key components of space health physiology, namely generalized tissue inactivity and ionizing radiation exposure. NASA has the facility of microgravity experiments combined with replicating the ionizing space environment. One advantage of the screening study was the development of a simple low-cost reproducible approach to simulate aspects of the space environment. The approach of encasing the SVF within packed radioactive torbernite allowed alpha, beta and gamma radiation from all directions to affect the cells to replicate $3 \mathrm{D}$ cosmic radiation experienced by astronauts. Partial representation of microgravity was achieved by keeping the cells in stasis in an Eppendorf tube as there were no physiological pressure effects from a functioning circulatory system. Pressure changes are a major influencing variable on 3D gels incorporating stem cells [14] [15]. The effect of stasis found in this study matched the detrimental effects of gamma radiation in cell health and tumor markers.

The temporal variables of stasis and gamma radiation showed a clear difference between short-term exposure with recovery (up to five days) compared with the longer-term interval of greater than eight days. The longer duration showed a dramatic and significant decrease in cell health and increased propensity for carcinogenesis. From a commercial space perspective where travel is greater than seven days then astronauts, future space miners and long-duration space tourists require careful monitoring. Furthermore, where medical radiation patients are recovering after treatment then mobilizing the patient as soon as possible would likely result in better outcomes.

A key objective in this study was to evaluate if a prototype PF could prevent cell damage and recover cells when exposed to noxious events of stasis and excessive ionizing radiation. The developed PF showed excellent potential to reduce the damaging effects by approximately $50 \%$. Migration studies of potentially cancerous cells were not performed in this study as the cells were vortexed and dissociated in saline for flow cytometry measurements. Optimizing and in- 
dividualizing the PF could be integrated into prescreening for cancer patients to improve outcomes, have fewer side effects and promote early return to meaningful employment. The cost of cancer in society is a staggering USD 1.16 trillion (2010 estimate) [16]. DNA double-strand breaks and increased risk of cancer are also a feature of the aging phenomenon. The PF arguably could improve health and longevity in the population. The cost of health in the aged population is estimated to be USD $\$ 98,000$ per person per year in the USA [17].

Similarly, improved protection for each astronaut could be assessed preflight in this laboratory test by screening an adipose or hematopoietic stem cell sample with the PF. The cost of each astronaut in the ISS is estimated to be $\$ 7$ million per day and maintaining their health is a priority. The space industry is growing exponentially and key figures in world business development such as Elon Musk and Jeff Bezos have strongly argued for lunar and asteroid space mining of resources such as helium-3 for nuclear fusion reactors and rare earth metals. Space health is a principle research priority to enable long-term space activities. The PF reduced carcinogenesis and DNA damage by approximately $50 \%$ when stem cells were exposed to a potentially equivalent time of 4 months on board the ISS.

The author has recently published how lightweight and portable stem cell technology could be used in the space environment for regenerative medicine aspects of astronaut health [11]. This current study showed that a low-cost method could assess cell health and cancer markers. The preliminary evaluation of the PF showed it to have three promising therapeutic effects: 1) prevent cell/DNA damage, 2) reduce cancer risk and 3) recover damaged and precancerous stem cells.

\section{Conflicts of Interest}

The author declares no conflicts of interest regarding the publication of this paper.

\section{References}

[1] Vickers, E., Liang, J., Vickers, P. and Wen, H. (2021) Regenerative Medicine to Reduce the Side Effects from Radiotherapy Causing Skin Cancer, Fibrosis, Neuropathic Pain and Hair Loss. Journal of Cancer Therapy, 12, 461-477. https://doi.org/10.4236/jct.2021.128040

[2] Lonceint, R., Bodéré, F. and Bénédicte, G. (2019) Risk Management through an “Activity Contradictions" Lens: Exposure to Low Doses of Radiation in Nuclear Medicine. Frontiers in Medicine, 6, Article No. 228. https://doi.org/10.3389/fmed.2019.00228

[3] Onorato, G., Di Schiavi, E. and Di Cunto, F. (2020) Understanding the Effects of Deep Space Radiation on Nervous System: The Role of Genetically Tractable Experimental Models. Frontiers in Physics, 8, Article No. 362. https://doi.org/10.3389/fphy.2020.00362

[4] Mah, L.J., El-Osta, A. and Karagiannis, T. (2010) $\gamma \mathrm{H} 2 \mathrm{AX}$ : A Sensitive Molecular Marker of DNA Damage and Repair. Leukemia, 24, 679-686.

https://doi.org/10.1038/leu.2010.6 
[5] Rhee, H.J., Kim, G.-Y., Huh, J.W., Kim, S.-W. and Na, D.S. (2000) Annexin I Is a Stress Protein Induced by Heat, Oxidative Stress and a Sulfhydryl-Reactive Agent. European Journal of Biochemistry, 267, 3220-3225. https://doi.org/10.1046/j.1432-1327.2000.01345.x

[6] Yang, J., Nie, J., Ma, X., et al. (2019) Targeting PI3K in Cancer: Mechanisms and Advances in Clinical Trials. Molecular Cancer, 18, 26. https://doi.org/10.1186/s12943-019-0954-x

[7] Li, L.T., Jiang, G., Chen, Q. and Zheng, J.N. (2015) Ki67 Is a Promising Molecular Target in the Diagnosis of Cancer (Review). Molecular Medicine Reports, 11, 1566-1572. https://doi.org/10.3892/mmr.2014.2914

[8] Guo, Y., Pan, W., Liu, S., Shen, Z., Xu, Y. and Hu, L. (2020) ERK/MAPK Signalling Pathway and Tumorigenesis (Review). Experimental and Therapeutic Medicine, 19, 1997-2007. https://doi.org/10.3892/etm.2020.8454

[9] Zakrzewski, W., Dobrzyński, M., Szymonowicz, M., et al. (2019) Stem Cells: Past, Present, and Future. Stem Cell Research and Therapy, 10, Article No. 68. https://doi.org/10.1186/s13287-019-1165-5

[10] Rosenstein, A.H. and Walker, V.K. (2021) Fidelity of a Bacterial DNA Polymerase in Microgravity, a Model for Human Health in Space. Frontiers in Cell and Developmental Biology, 9, Article ID: 702849. https://doi.org/10.3389/fcell.2021.702849

[11] Vickers, E.R. and Wen, H. (2021) Stem Cell and Regenerative Methods for Space Personnel. Stem Cells and Regenerative Medicine, 5, 1-13.

https://scivisionpub.com/pdfs/stem-cell-and-regenerative-methods-for-space-perso nnel-1723.pdf

[12] Gong, C., Yang, Z., Zhang, L., Wang, Y., Gong, W. and Liu, Y. (2017) Quercetin Suppresses DNA Double-Strand Break Repair and Enhances the Radiosensitivity of Human Ovarian Cancer Cells via P53-Dependent Endoplasmic Reticulum Stress Pathway. OncoTargets and Therapy, 11, 17-27. https://doi.org/10.2147/OTT.S147316

[13] Liang, S., Niu, Y., Shin, K. and Cui, X. (2017). Protective Effects of Coenzyme Q10 on Developmental Competence of Porcine Early Embryos. Microscopy and Microanalysis, 23, 849-858. https://doi.org/10.1017/S1431927617000617

[14] Xue, B., Tang, D., Wu, X., et al. (2021) Engineering Hydrogels with Homogeneous Mechanical Properties for Controlling Stem Cell Lineage Specification. Proceedings of the National Academy of Sciences, 118, e2110961118. https://doi.org/10.1073/pnas.2110961118

[15] Sommerfeld, S.D. and Elisseeff, J.H. (2016) Time to Relax: Mechanical Stress Release Guides Stem Cell Responses. Cell Stem Cell, 18, 166-167.

https://doi.org/10.1016/j.stem.2016.01.020

[16] World Health Organization (2010) Cancer Fact Sheet. https://www.who.int/news-room/fact-sheets/detail/cancer

[17] De Nardi, M., French, E., Bailey Jones, J. and McCauley, J. (2015) Bulletin on Aging and Health, No. 2. https://www.nber.org/bah/2015no2/medical-spending-elderly 